\title{
The investigation of situation of Taiwan adult civilians' retrieving science or technology related information on the Internet
}

\author{
Yuan-Chueh Tseng \\ Graduate Institute of Science Education, \\ National Kaohsiung Normal University \\ GISE, NKNU \\ Kaohsiung City, Taiwan, R.O.C. \\ jjjj_1204@yahoo.com.tw
}

\author{
Jeng-Fung Hung \\ Department of Science Education, \\ National Kaohsiung Normal University \\ GISE, NKNU \\ Kaohsiung City, Taiwan, R.O.C \\ t1873@nknucc.nknu.edu.tw
}

\begin{abstract}
This study investigated the public information sources in science or technology in Taiwan. A survey was conducted extensively in Taiwan to study civic network scientific literacy. Participants of this study included 2,024 individuals who were selected by using probability proportional to size sampling method. Interviews were conducted and survey data were quantitatively analyzed by used percentage and reported with the cross tables. The result showed that: (1) The primary science or technology information sources used by Taiwanese adult citizens were TV, newspapers and Internet. (2)Young citizens possessing the higher education placed a high value to retrieve science or technology information on the Internet. (3)People with higher education levels have higher Internet usage rates to retrieve science or technology information.
\end{abstract}

Keywords-Internet, scientific literacy, network scientific literacy, information sources

\section{INTRODUCTION}

The 21st Century is an era of knowledge explosion. With information changing every day, the advancing speeds of science and technology are far beyond our imagination. Therefore, in order to meet the various challenges of a new century, worldwide countries are endeavored to researches of various new technologies and sciences, and at the same time are trying actively to improve the basic "science education", so that our next generation may be equipped with sound "scientific literacy".

The research on understanding of scientific experience of the American public began with the 1957 U.S. wide investigation. The European Community initiated a public scientific literacy investigation in 15 countries in 1989. China first conducted a public scientific literary sampling investigation in Beijing in 1989. In order to analyze public attitudes toward and understanding of science and technology, and to provide conclusive information on fields, qualities and vitality related to science, the National Science Foundation (NSF) has conducted the Survey of Public Attitudes Toward and Understanding of Science and Technology every two years since 1976 . The survey reports are presented in the "Science and Engineering Indicators" report as reference for future policy development [1, 2, 3].

As there is currently no physical study for investigating the adult citizens' understanding of science or technology skills, this study is the first to investigate massively the "network scientific literacy" of adult citizens in Taiwan. This study primarily analyzes the current conditions of public retrieval of "science or technology related information" in hope to provide physical information as a decisive indicator for lifetime education and policy establishment.

\section{A. Purpose of research}

This study aims at discussing the current conditions of retrieval of science or technology related information on the Internet in Taiwan, and discussing the conditions of retrieval of " science or technology related information" based on the gender, age and education of the adult citizens.

\section{B. Research problem}

- What is the sequence followed when adult citizens in Taiwan retrieve "science or technology related information”?

- Based on different genders, ages and educations, how is the usage of Internet by adult citizens in Taiwan for retrieval of "science or technology related information"?

\section{Glossary}

\section{Scientific Literacy}

Knowledge of important scientific terms, understanding of scientific methods and processes, and value toward modern social and cultural situations; that is, scientific literacy includes nature of science, knowledge of science, and impact of cognitive science and technology on society [4, $5,6]$.

\section{Network Scientific Literacy}

As information network is easy to use and convenient, the public can actively acquire more information. Thus, the relationship between science and media should be considered from multiple dimensions, including whether the public can receive science related information cognitively, and whether they can acquire science related information actively. This study aims to the situation the Taiwan adult civilians' retrieving science and technology related information on the Internet. It’s named "Network Scientific Literacy”. 


\section{Research Methodology}

\section{A. Study subject and sampling}

The research matrix of this study consists of Taiwan citizens over the age of 18 (born before Dec. 31, 1989). This study samples cases applying the probability proportional to size sampling (PPS) based on the household register of the Department of Household Registration, Ministry of the Interior(M.O.I.). The program for the three stage sampling is: (1) Use systematic sampling to extract a certain number of cities and townships according to the population of each level; (2) Use the same sampling method to extract a certain number of villages from each city and townships; (3) Use the same sampling method to extract a certain number of cases from each village.

After selecting the village to be interviewed, the Humanities and Social Sciences Investigation Project Research Center of Academia Sinica sent an official letter to the Department of Household Registration, M.O.I. to applying for the registration information of the village, and a certain number of interviewees were then extracted from the household registration information and printed into a sample list. Interviewers visited people according to the names and addresses on the sample list and found qualified interviewees to conduct interviews.

The sample quantity of the study design included 4448 respondents, whereas a total of 2078 questionnaires were returned from Taiwan through interview. The 54 invalid questionnaires, including self-filling of respondents, wrong respondents, telephone visits, refusal of interview, and falsification were deducted, yielding 2024 valid questionnaires with a ratio of $97.4 \%$.

\section{B. Research tools}

The tool used in this study is the "Questionnaire on Public Scientific Literacy”. The first edition was translated from the "Survey of Public Attitudes Toward and Understanding of Science and Technology" by National Science Foundation (NSB, 2006) [2], of which the questions were examined by seven domestic professors related to scientific education fields before becoming the pre-test questionnaire. The pre-test questionnaire was distributed to students in two technical universities and one college of medical care and management in southern Taiwan. With the 114 questionnaires retrieved, 11 were invalid, leaving a total of 103 valid questionnaires. After the pre-test, the questions were modified for clarity and a formal survey was formed.

\section{Data processing and analyzing}

The study applied SPSS12.0 for data analysis. Question one is used to fully understand the public retrieval of "science or technology related information"; question two is used to understand the retrieval of "science or technology related information” through the Internet based on gender, age and education in a homogeneous Chi-square test.

\section{RESULT}

This study is divided into two parts, and the results are as follows:

\section{A. Retrieval of " science or technology related information”}

For retrieval of "science or technology related information", most adult citizens in Taiwan choose: TV (94.3\%), newspapers $(57.3 \%)$ and Internet $(50.7 \%)$, followed by magazines (47.6\%), books and other printings (30.0\%), friends/colleagues (29.1\%), family (18.9\%), broadcasting stations (14.9\%), school (8.1\%) and government technical sectors (4.5\%)(See Table 1. for details).

TABLE 1. PERCENTAGE AND SEQUENCE OF RETRIEVAL OF "SCIENCE OR TECHNOLOGY” RELATED INFORMATION

\begin{tabular}{|l|c|}
\hline Information Source & science or technology \\
\hline (01) Newspapers & 57.3 【2】 \\
\hline (02) Magazines & 47.6 \\
\hline (03) Internet & 50.7 【 】 \\
\hline (04)Books/other printings & 30.0 \\
\hline (05) TV & 94.3 【 】 \\
\hline (06)Broadcasting stations & 14.9 \\
\hline (07)Technical sectors of the government & 4.5 \\
\hline (08)Family & 18.9 \\
\hline (09)Friends/colleagues & 29.1 \\
\hline (10)School & 8.1 \\
\hline
\end{tabular}

Note: 【】 show the sequential numbers of the percentages; only the top three are shown

\section{B. Retrieval of " science or technology related information" by different publics through Internet}

There is a slight difference in the gender variable in that the number of males exceeds females. For the age category, the Internet usage rate is higher for younger people, and it gradually decreases with age; in general, the usage rate of those below 50 years old is around $85 \%$, while that of those above 50 is around 15\%. As for the education variable, those who received education above colleges have the highest Internet usage rate, which is close to $70 \%$, and those whose education is below junior high have the lowest usage rate, which is less than $10 \%$ (See Table 2 . for details).

TABLE 2. TABLE OF HOMOgENEOUS CHI-SQUARE TEST FOR RETRIEVAL OF “SCIENCE OR TECHNOLOGY RELATED INFORMATION" ON THE INTERNET

\begin{tabular}{|c|c|c|c|c|}
\hline \multicolumn{2}{|c|}{ Variable } & \multirow{2}{*}{$\begin{array}{c}\text { Number } \\
564\end{array}$} & \multirow{2}{*}{$\begin{array}{c}\begin{array}{c}\text { Percentage } \\
(\%)\end{array} \\
53.0\end{array}$} & \multirow{2}{*}{$\begin{array}{c}\begin{array}{c}\text { Chi-square } \\
\text { value }\end{array} \\
9.132 *\end{array}$} \\
\hline Gender & Male & & & \\
\hline & Female & 501 & 47.0 & \\
\hline \multirow[t]{5}{*}{ Age } & $18 \sim 29$ & 408 & 38.3 & \multirow{5}{*}{$848.072 * * *$} \\
\hline & $30 \sim 39$ & 340 & 32.0 & \\
\hline & $40 \sim 49$ & 210 & 19.7 & \\
\hline & $50 \sim 59$ & 90 & 8.5 & \\
\hline & Above 60 & 16 & 1.5 & \\
\hline \multirow[t]{3}{*}{ Education } & $\begin{array}{c}\text { Below junior } \\
\text { high }\end{array}$ & 54 & 5.1 & \multirow{3}{*}{$943.371 * * *$} \\
\hline & High school & 306 & 28.8 & \\
\hline & $\begin{array}{l}\text { Above } \\
\text { college }\end{array}$ & 704 & 66.2 & \\
\hline
\end{tabular}




\section{DISCUSSION}

The results discovered that TV, newspapers and Internet are the main channels for retrieving information. The age and education variables can be used to explain whether the adult citizens in Taiwan use the Internet for retrieval of "science or technology related information”. This indicates that, For the new generation, using the Internet for retrieval of science or technology related information is quite common. In addition, people with higher education levels would have higher Internet usage rates. Horrigan (2006) indicated that those who use the Internet to search for science and technology related messages have a better understanding of science [7]. The reference is the same as our result. People who have higher education of understanding science, would get used to retrieving science and technology related information by Internet.

\section{CONCLUSIONS}

The results discovered that TV, newspapers and Internet are the main channels. The Internet usage rate of young people is high, and it decreases with age. People with higher education levels have higher Internet usage rates.

\section{RESEARCH SUGGESTION}

The study is reference to the (B) information source and interest from the questionnaire on "A Survey of understanding, interests and care for science and technology.” The nationals can focus on the interest and information resource for science and technology while the design of the questionnaire content merely aims to general inquiry. It is the limitation for this study. For future researchers, they are suggested to design a more detailed questionnaire content with more information on understanding the phenomenon why the Internet usage rate of people with younger ages or with higher education level is much higher than others. It's the research suggestion for the further improvement.

\section{ACKNOWLEDGMENT}

Data analyzed in this paper (book, monograph) were collected in the first cycle's survey of the research project "Public Attitudes Toward and Understanding of Science and Technology". The project was conducted by the Institute of Science Education, National Kaohsiung Normal University and sponsored by the National Science Council, Taiwan.

\section{REFERENCES}

[1] National Science Board. Science and Engineering Indicators - 2006. Arlington, VA: National Science Foundation. Retrieved Sep. 23, 2007, from the World Wide Web: www.nsf.gov/statistics/seind04/, 2004.

[2] National Science Board. Science and Engineering Indicators - 2006. Arlington, VA: National Science Foundation. Retrieved Sep. 23, 2007, from the World Wide Web: www.nsf.gov/statistics/seind06/, 2006.

[3] National Science Board. Science and Engineering Indicators - 2008. Arlington, VA: National Science Foundation. Retrieved Jun. 1, 2008, from the World Wide Web: www.nsf.gov/statistics/seind08/, 2008.

[4] Bybee , R. W. Achieving scientific literacy - From purposes to practices. Portsmouth. NH, USA: Heineman, 1997.

[5] Miller, J. D. Scientific literacy: A conceptual and empirical review. Daedalus, 1983, vol. 112(2), pp. 29-48.

[6] Miller, J. D., Augenbraun, E., Schulhof, J., \& Kimmel, L. G. Adult science learning from local television newscasts. Science Communication, 2006, vol. 28(2), pp. 216-242.

[7] Horrigan, J. B. The Internet as a Resource for News and Information about Science. Retrieved May 25, 2009, from http://www.pewinternet.org/Reports/2006/The-Internet-as-aResource-for-News-and-Information-about-Science.aspx, 2006.

[8] American association for the advancement. Project 2061: Science for all Americans. Washington D.C.: Author. Abell , S.K., \& Smith , D.C.(1994). What is science? : Preservice elementary teacher conceptions of science. International Journal of Science education, 1989, pp. 475-487.

[9] Cheng, J. C., Tseng, Y. C., Chou, C. Y., Wu, Y. Y., Chiu, H. L., Liu, C. J., Hong, J. F., Zhao, D. W., \& Huang, T. C. Information Sources and Interest in Science and Technology in Taiwan. The International Conference of East-Asian Science Education, Taipei, Taiwan, 2009.

[10] Ho, T. Y., \& Huang, T. C. National Scientific Literacy-Analysis of Data Source. The 23rd Symposium on Science Education Academics, Taipei, Taiwan, 2007. 